\title{
Pathologic analysis, diagnosis and treatment of adrenal myelolipoma
}

\author{
Heng-chuan Su, MD; Xin Huang, MD; Wen-long Zhou, MD; Jun Dai, MD; Bao-xing Huang, MD; \\ Wan-li Cao, MD and Fu-kang Sun, MD
}

Heng-Chuan Su and Xin Huang contributed equally to this work.

Department of Urology, Ruiijn Hospital, School of Medicine, Shanghai Jiaotong University, Shanghai, China

Cite as: Can Urol Assoc J 2014;8(9-10):e637-40. http://dx.doi.org/10.5489/cuaj.422 Published online September 9, 2014.

\section{Abstract}

With the widespread use of non-invasive imaging modalities, the incidental detection of myelolipoma has become more common. We analyze the clinical data of 4 typical cases of unilateral adrenal myelolipomas, including 1 hormonally inactive patient and 3 hormonally active cases with hyperaldosteronemia, hypercortisolism and hyperandrogenemia. Obvious differences were found in the pathological sections. To our knowledge, this is the first article discussing the etiology of adrenal myelolipoma from pathologic analyses.

\section{Introduction}

Adrenal myelolipoma is a benign tumour-like lesion composed of mature adipose tissue admixed with hematopoietic elements of various proportions. Today, with the widespread use of non-invasive imaging modalities, incidental detection of myelolipoma has become more common, constituting up to $10 \%$ to $15 \%$ of incidental adrenal masses. ${ }^{1}$ Although adrenal myelolipoma is a non-functioning tumour, its association with adrenocortical dysfunction has occasionally been reported. These patients usually have abnormalities of adrenocortical hormones, such as Cushing's syndrome, Conn's syndrome, pheochromocytoma and virilization. ${ }^{2}$

We report 4 typical cases of adrenal myelolipomas, including 3 cases associated with adrenocortical dysfunction and 1 hormonally inactive case. At the microscopic level, obvious differences were found in the pathological sections. Hyperplasia of different zona of adrenal cortex was found in different types of hormonally active adrenal myelolipoma, with mature adipose tissue and hematopoietic elements in the adrenal tissues. This supports a theory that myelolipoma and atypical hyperplasia of adrenal cortex may be anatomically and functionally related. ${ }^{3}$ To our knowledge, this is the first article discussing the etiology of adrenal myelolipoma from pathologic analyses.

\section{Case 1}

A 48-year-old woman was referred to the hospital due to persistent hypokalemia and refractory hypertension. On laboratory examination, the patient showed high plasma aldosterone and suppressed plasma renin activity. Abdominal sonography showed a circular soft tissue mass of $2.3 \times 1.5 \times 1.0 \mathrm{~cm}$ in the right adrenal gland. The computed tomography (CT) scan revealed a suprarenal and encapsulated, well-circumscribed tumour consisting of fat and marrow tissues. Captopril-challenge test and saline-loading test indicated primary aldosteronism, and adrenal vein sampling (AVS) revealed an increased plasma aldosterone in the right adrenal gland. Therefore, we diagnosed the patient with adrenal myelolipoma associated with hyperaldosteronemia.

The patient underwent laparoscopic unilateral adrenal tumour resection plus ipsilateral adrenalectomy. The tumour weighed $90 \mathrm{~g}$, consisting of a round, brownish mass measuring $3.5 \times 3.0 \times 2.0 \mathrm{~cm}$. The histological study showed fusion of myelolipoma elements and hyperplasia of the adrenal cortex (zona glomerulosa). At the microscopic level, we saw a typical cell pattern of zona glomerulosa, with scattered hematopoietic elements. These cells were cuboidal or low columnar in shape, arranging in spherical masses (Fig. 1). After the operation, the physiological parameters, such as blood pressure and serum potassium, returned to normal.

\section{Case 2}

A 32-year-old female was referred to our hospital for hypertension and edema in both legs. A year before, she presented with central obesity, thinning of the skin and buffalo hump. 
Su et al.

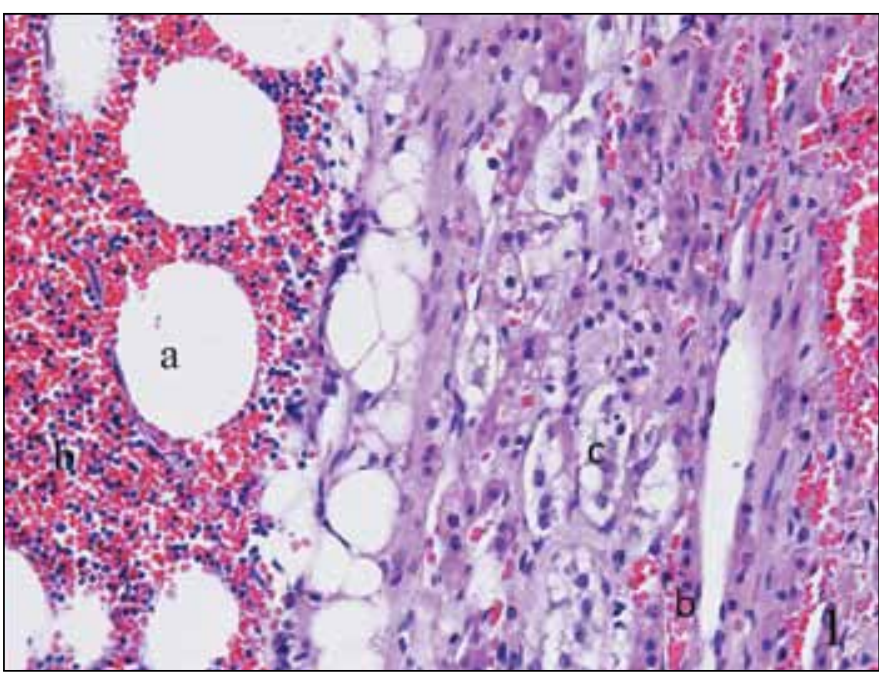

Fig. 1. Histological examination showed a typical myelolipoma composed of mature adipocytes (a), hematopoietic elements (b) and cells of zona glomerulosa (c), with hematopoietic elements(b) being among the adrenal tissues.

On laboratory examination, the patient showed decreased adrenocorticotropic hormone (ACTH), elevated levels of cortisol in plasma and urine. Normal circadian rhythm in cortisol secretion was lost. Half a year ago, she began to show menstruation disorder, which manifested as irregular periods and low blood volume. Abdominal sonography indicated a hyperecho mass in the right adrenal gland. The CT scan showed no abnormality in the pituitary gland, and a lesion in the right adrenal gland containing fat and specs of calcification. Therefore, we diagnosed this patient with adrenal myelolipoma associated with hypercortisolism.

The patient underwent laparoscopic right adrenal tumour resection plus ipsilateral partial adrenalectomy. During the operation, a grey mass adjoining the right adrenal gland and measuring $4 \times 3 \times 2 \mathrm{~cm}$ was removed. The mass weighed $110 \mathrm{~g}$ and the cut surface appeared yellowish to dark-brown in colour. The histological study showed fusion of myelolipoma elements and hyperplasia of the adrenal cortex (zona fasciculata). Typical cell patterns of zona fasciculate, which were large and filled with lipoid vesicles, were found in the pathological section, with scattered mature adipose tissue and hematopoietic elements (Fig. 2). After surgery, endocrine function of this patient returned to normal. At the 5 -year follow-up, the patient's disease did not recur.

\section{Case 3}

Our third case is a 34-year-old woman with normal intelligence and 46XX karyotype, with a history of growth retardation (height $127 \mathrm{~cm}$, weight $34 \mathrm{~kg}$ ), virilization (including hirsutism, hoarse voice and menoxenia) and lumbago. Here abdominal sonography showed a circular soft mass of $5.7 \times 4.9 \times 3.2 \mathrm{~cm}$ in the right adrenal gland and no obvious

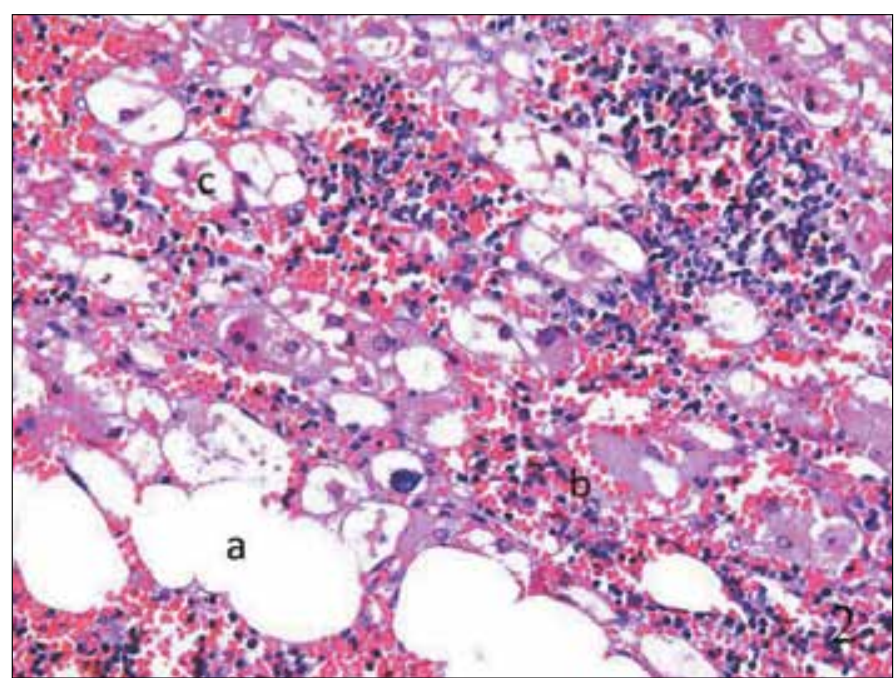

Fig. 2. The histological study showed fusion of mature adipocytes (a), hematopoietic elements (b) and hyperplasia of zona fasciculata of the adrenal cortex (c), with adipose tissue (a) and hematopoietic elements (b) being among the adrenal tissues.

abnormality in the uterus and ovaries. A right adrenal tumour that was predominantly fatty with tiny foci of calcification was found by CT. Endocrine examinations showed increased plasma testosterone and dehydroepiandrosterone sulfate, significantly decreased follicle-stimulating hormone and luteinizing hormone, with other biochemical parameters being basically normal. Therefore, we diagnosed the patient with adrenal myelolipoma associated with hyperandrogenemia.

The patient opted for a laparoscopic unilateral adrenal tumour resection plus ipsilateral adrenalectomy. The mass resected measured $7 \times 5 \times 4 \mathrm{~cm}$, was encapsulated and weighed $270 \mathrm{~g}$. At the microscopic level, the lesions were composed of mature adipose tissue, hematopoietic cells and hyperplasia of zona reticularis of adrenal cortex. Scattered adipose tissue and hematopoietic elements were among cells of zona reticularis, which were arranged in irregular nests or cords, woven into a network (Fig. 3). After the surgery, she recovered quickly. As time went on, the symptoms of hyperandrogenemia disappeared.

\section{Case 4}

Our fourth case is a 38-year-old woman whose disease was discovered incidentally by abdominal CT during a physical examination due to abdominal pain. The laboratory results showed no metabolic or adrenocortical dysfunction (Table 1). Abdominal sonography showed a circular mass in the adrenal gland. The CT scan showed an adrenal mass of $7.0 \times 6.0 \times 4.0 \mathrm{~cm}$, which was fatty with interspersed areas of ill-defined solid tissue and tiny foci of calcification. Based on these appearances, a presumptive diagnosis of hormonally inactive adrenal myelolipoma was made. Since this patient refused the operation, she left the hospital. 


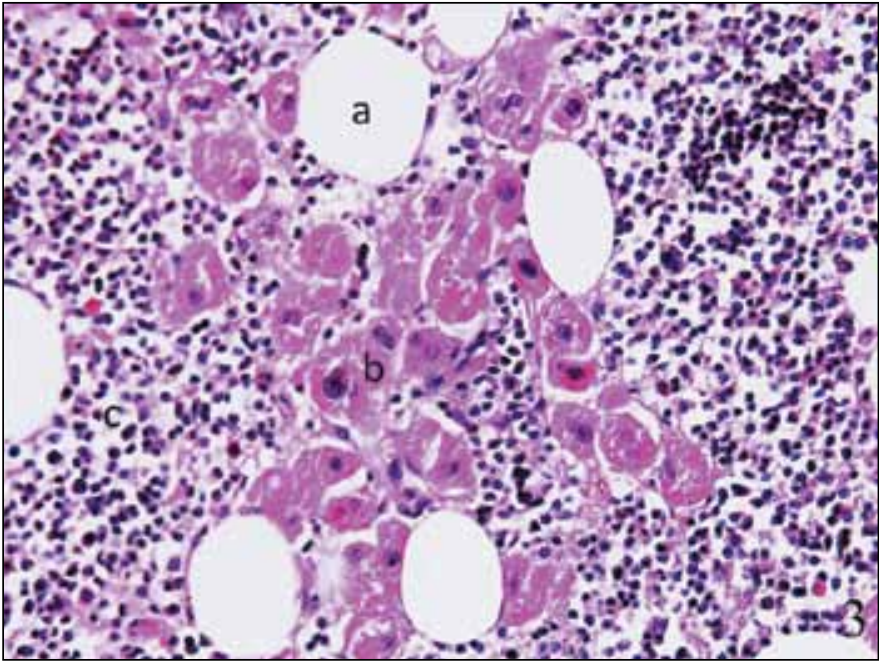

Fig. 3. At the microscopic level, the lesions were composed of mature adipose tissue (a), scattered islands of hematopoietic cells (b), and hyperplasia of the adrenal cortex (zona reticularis) (c), with adipose tissue (a) and hematopoietic elements (b) being among the adrenal tissues.

Half a year later, this patient was admitted to hospital emergently due to hemorrhagic shock and a continuously enlarging retroperitoneal mass. Her hemoglobin level was only $40 \mathrm{~g} / \mathrm{L}$. Tumour rupture and retroperitoneal diffuse hemorrhage were discovered during exploratory surgery. Since the kidney and right adrenal were undistinguishable, tumorectomy, adrenalectomy and homolateral nephrectomy were required. After the surgery, a giant myelolipoma larger than $9 \mathrm{~cm}$ could be found in the surgical specimen. The pathological sections of myelolipoma showed tumour of mature fat tissue and bone marrow elements. There were no adipose tissues or hematopoietic elements in the surrounding adrenal tissues (Fig. 4). This patient recovered after surgery and at the 3-year follow-up, she was free of recurrence.

\section{Discussion}

The mechanism of adrenal myelolipoma associated with adrenocortical dysfunction remains unclear. Inuzuka and colleagues ${ }^{4}$ report a case of myelolipoma associated with primary aldosteronism. Aldosterone hypersecretion from

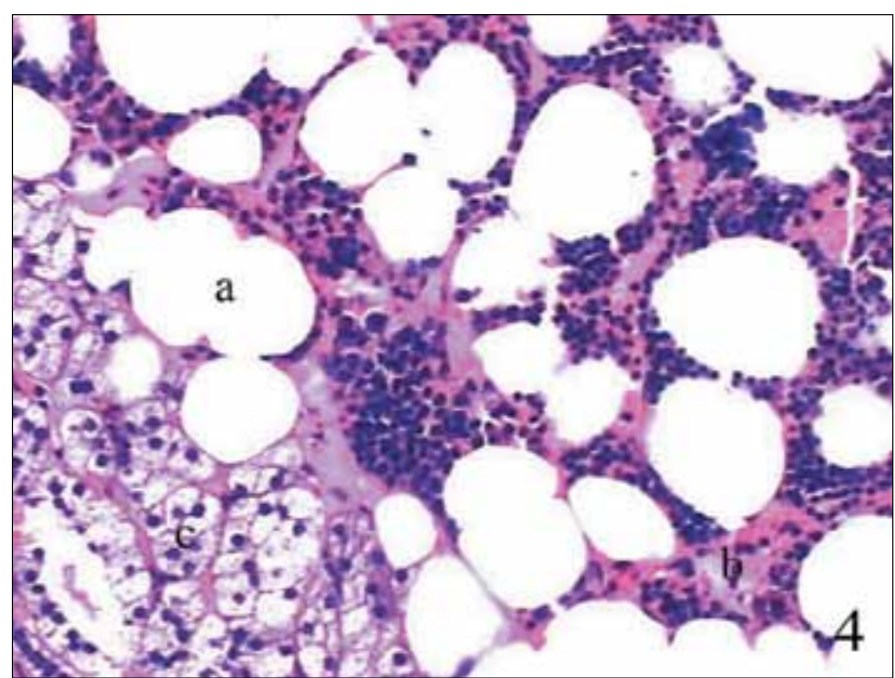

Fig. 4. The pathological sections of these patients showed tumour comprised mature fat tissue (a) and bone marrow element (b), with no adipose tissue and hematopoietic elements being among the adrenal tissues (c).

bilateral adrenal glands had been confirmed by AVS, but this patient was cured after surgical removal of the unilateral adrenal gland together with myelolipoma. Therefore the authors concluded that myelolipomas may release some factors which could stimulate aldosterone secretion in adrenal glands. However, Camarero and colleagues ${ }^{5}$ believed the pressure exerted by large size of myelolipoma may cause the development of endocrine disorder.

In our study, obvious differences were found in the pathological sections of hormonally active and hormonally inactive cases. Mature adipose tissue and hematopoietic elements existed in the surrounding adrenal tissues in hormonally active cases, which indicated that extrinsic compression may contribute to the development of anatomical and functional abnormality of adrenal cortex. The persistent excessive stimulation by hormones secreted by abnormal adrenal cortex might also play a role as a mediator in transforming adrenal tissue into myeloid cells and fatty replacement in hormonally active cases. ${ }^{6,7}$ Therefore, on the basis of aforementioned experts' views and our discovery, adrenal myelolipoma and atypical hyperplasia of adrenal

\begin{tabular}{|c|c|c|c|c|c|c|c|c|c|}
\hline Case & Gender & $\begin{array}{l}\text { Age, } \\
\text { year }\end{array}$ & $\begin{array}{c}\text { Serum } \\
\text { potassium, } \\
\text { mmol/L }\end{array}$ & $\begin{array}{c}\text { Serum } \\
\text { aldosterone, } \\
\text { pmol/L }\end{array}$ & $\begin{array}{c}\text { Serum } \\
\text { cortisol, } \\
\mathrm{nmol} / \mathrm{L}\end{array}$ & $\begin{array}{c}\text { 24-hour urine } \\
\text { cortisol, } \\
\text { nmol }\end{array}$ & $\begin{array}{l}\text { Serum } \\
\text { ACTH, } \\
\text { pmol/L }\end{array}$ & $\begin{array}{c}\text { Serum } \\
\text { testosterone, } \\
\text { ng/mL }\end{array}$ & $\begin{array}{c}\text { Dehydroepiandro- } \\
\text { sterone sulfate, } \\
\text { ug/dL }\end{array}$ \\
\hline 1 & Female & 48 & 2.1 & 963 & 440 & 270 & 7.9 & 0.7 & 411 \\
\hline 2 & Female & 32 & 4.3 & 155 & 980 & 560 & 3.5 & 0.4 & 305 \\
\hline 3 & Female & 34 & 3.9 & 258 & 360 & 240 & 8.9 & 2.4 & 968 \\
\hline 4 & Female & 38 & 4.4 & 198 & 280 & 150 & 12.5 & 0.5 & 449 \\
\hline $\begin{array}{l}\text { Normal } \\
\text { range }\end{array}$ & & & $\begin{array}{c}3.5-5.1 \\
\mathrm{mmol} / \mathrm{L}\end{array}$ & $\begin{array}{l}\text { 133-393 } \\
\mathrm{pmol} / \mathrm{L}\end{array}$ & $\begin{array}{c}220-660 \\
\mathrm{nmol} / \mathrm{L}\end{array}$ & $30-300 \mathrm{nmol}$ & $\begin{array}{l}5.1-18.9 \\
\mathrm{pmol} / \mathrm{L}\end{array}$ & $\begin{array}{c}0.13-1.08 \\
\mathrm{ng} / \mathrm{mL}\end{array}$ & $56.2-511.7 \mathrm{ug} / \mathrm{dL}$ \\
\hline
\end{tabular}

ACTH: adrenocorticotropic hormone. 
Su et al.

cortex may be anatomically and functionally related in hormonally active cases.

The imaging characteristics of hormonally inactive and hormonally active adrenal myelolipomas are similar - dense fatty tissue is the diagnostic key. ${ }^{8}$ Abdominal sonography showed a solid mass in the diseased adrenal, with strong echo in the area of fat component and low echo in the area of marrow tissues. On CT, the typical image usually revealed a suprarenal and encapsulated, well-circumscribed tumour with fat and marrow tissues. ${ }^{9}$ After administering intravenous contrast, there was no enhancement of solid components in the adrenal tumour, which was the main diagnostic key from other solid adrenal mass. The magnetic resonance image can help distinguish the origin of the tumour and assess tissues planes for surgical planning. ${ }^{9}$ There was high signal intensity on the T1-weighted images because of adipose tissue and intermediate signal intensity on the T2-weighted images due to mixed fat and marrow tissues. The definite diagnosis of adrenal myelolipoma relies mainly on pathological examination, which revealed mainly mature adipose tissue and scattered hematopoietic cells. ${ }^{10}$

In adrenal myelolipoma associated with endocrine disorders, we found that hyperplasia or neoplasia of adrenal cortex usually coexisted with myelolipoma, which could account for the hormonal activity. In our series, 3 patients had hypercortisolism, hyperaldosteronemia and hyperandrogenemia, with the histological study showing adrenal myelolipomas with hyperplasia of zona glomerulosa, zona fasciculata and zone reticularis. Therefore it is necessary to identify these differences and make a correct diagnosis.

The histological data of myelolipoma associated with primary hyperaldosteronism showed high plasma aldosterone, hypokalemia and suppressed plasma renin activity; the histological study showed a myelolipoma with hyperplasia of glomerulosa cells (Fig. 1). ${ }^{6,11}$ The endocrinological data of myelolipoma associated with Cushing syndrome showed increased cortisol and suppressed ACTH; the histological study showed fusion of myelolipoma elements and hyperplasia of zona fasciculate (Fig. 2). ${ }^{2}$ The endocrinological data of myelolipoma associated with hyperandrogenemia showed significantly increased plasma testosterone and dehydroepiandrosterone sulfate (DHEAS), and the histological study showed myelolipoma elements and hyperplasia of zona reticularis of adrenal cortex (Fig. 3). ${ }^{12}$

\section{Conclusion}

The management of adrenal myelolipoma should be individualized. The first step in diagnostic workup of this disease is to assess the hormonal activity to differentiate hormonally active cases from other cases. Surgery is appropriate for hormonally active myelolipoma, growing tumours and tumours larger than $4 \mathrm{~cm}$ to reduce the risk of life-threatening hemorrhage - case 4 illustrates this. For patients with smaller lesions (less than $4 \mathrm{~cm}$ in diameter), watchful waiting is appropriate. ${ }^{1}$ Castillo and colleagues ${ }^{13}$ advocate laparoscopic adrenalectomies for this disease and they believed tumour size does not preclude the indications for laparoscopic approach even if it was greater than $5 \mathrm{~cm}$. We agree with this concept.

Acknowledgements: This work was supported by the grant from the Shanghai Municipal Natural Science Foundation (№. 10411960000).

Competing interests: Dr. H. Su, Dr. X. Huang, Dr. Zhou, Dr. Dai, Dr. B. Huang, Dr. Cao and Dr. F. Sun all declare no competing financial or personal interests.

This paper has been peer-reviewed.

\section{References}

1. Daneshmand S, Quek ML. Adrenal myelolipoma: diagnosis and management. Urol J 2006;3:71-4.

2. Hisamatsu H, Sakai H, Tsuda S, et al. Combined adrenal adenoma and myelolipoma in a patient with Cushing's syndrome: Case report and review of the literature. Int I Urol 2004;1 1:416-8. http://dx.doi. org/10.1111/i.1442-2042.2004.00815.x

3. Kanj HA, Noronha J, D'Aguillo AF, et al. Bilateral adrenal myelolipomas with Cushing's syndrome. JAMA 1988;259:3034-6. http://dx.doi.org/10.1001/jama.1988.03720200056034

4. Inuzuka $M$, Tamura $N$, Sone $M$, et al. A case of myelolipoma with bilateral adrenal hyperaldosteronism cured after unilateral adrenalectomy. Intern Med 2012;51:479-85. http://dx.doi.org/10.2169/ internalmedicine.51.5777

5. Camarero-Temi-0 V, Mercado-Oriz V, Hijazi-Prieto B, et al. Adrenal myelolipoma associated with primary hyperaldosteronism. Nefrologia 2012;32:124-5.

6. Sakaki M, Izaki H, Fukumori T, et al. Bilateral adrenal myelolipoma associated with adrenogenital syndrome. Int J Urol 2006;13:801-2. http://dx.doi.org/10.1111/i.1442-2042.2006.01406.x

7. Ide H, Terado Y, Nakagawa $\mathrm{T}$, et al. Incidentally discovered adrenal myelolipoma associated with hyperthyroidism. Int I Clin Oncol 2007;12:379-81. http://dx.doi.org/10.1007/s10147-007-0662-1

8. Babinska A, Nałecz A, Swiatkowska-Stodulska R, et al. Adrenal myelolipomas composed with adrenal nodular hyperplasia in the same gland. Pol J Pathol 2012;63:45-8.

9. Meyer A, Behrend M. Presentation and therapy of myelolipoma. Int I Urol 2005;12:239-43. http:// dx.doi.org/10.1111/i.1442-2042.2005.01034.x

10. Talwalkar SS, Shaheen SP 2nd. Extra-adrenal myelolipoma in the renal hilum: A case report and review of the literature. Arch Pathol Lab Med 2006;130:1049-52.

11. Jung SI, Kim SO, Kang TW, et al. Bilateral adrenal myelolipoma associated with hyperaldosteronism:report of a case and review of the literature. Urology 2007;70:1223.e11-3.

12. Su HC, Huang X, Dai J, et al. Adrenal myelolipoma associated with hyperandrogenemia. Int I Urol 2012;19:1026-8. http://dx.doi.org/10.1111/j.1442-2042.2012.03100.x

13. Castillo $\mathrm{OA}$, Vitagliano $\mathrm{G}$, Cortes 0 , et al. Laparoscopic adrenalectomy for adrenal myelolipoma. Arch Esp Urol 2007;60:217-21. http://d x.doi.org/10.4321/S0004-06142007000200022

Correspondence: Prof. Fu-kang Sun, Department of Urology, Ruijin Hospital, School of Medicine, Shanghai Jiaotong University, No.197, Ruijin Er Road, Shanghai 200025, China; sunfukangb@126.com 